\title{
Batch Number
}

National Cancer Institute

\section{Source}

National Cancer Institute. Batch Number. NCI Thesaurus. Code C104504.

A distinctive alpha-numeric identification code assigned by the manufacturer or distributor to a specific quantity of manufactured material or product that is produced in a manner that is expected to render it homogeneous. 